\title{
O cuidado e a Redução de Danos como Promotores de Saúde no Território da Cracolândia
}

\author{
Paola de Oliveira Camargo, ${ }^{1}$ Michele Mandagará de Oliveira, ${ }^{1}$ \\ Camila Irigonhé Ramos, ${ }^{2}$ Gabriela Botelho Pereira ${ }^{1}$
}

\begin{abstract}
RESUMO
O presente estudo buscou compreender as questões que envolvem as condições de saúde e de doença das pessoas que usam drogas e/ou se encontram em situação de rua no território da Cracolândia. Foi realizada observação participante e a elaboração de diário de campo, assim como entrevistas etnográficas com os participantes, os quais foram as pessoas que estavam no território da Cracolândia e os redutores de danos que trabalhavam no local. Para a análise dos dados utilizou-se o Interpretativismo, ou Teoria Interpretativa. Os resultados demonstraram que o território da Cracolândia pode apresentar circunstâncias que geram doenças, mas, também, ser um local de promoção da saúde e cuidado.

Palavras-chave: Saúde. Doença. Cuidado integral. Cocaína. Crack. Território.

THE CARE AND HARM REDUCTION AS HEALTH PROMOTERS IN THE TERRITORY OF CRACOLÂNDIA

\section{ABSTRACT}

This study was searchi comprehend the questions about the conditions of healf and disease of the people who use drugs and / or are homeless in the territory of Cracolândia. Participant observation and field diary construction were performed, as well as ethnographic interviews with participants. These were the people who were in the territory of Cracolândia and the damage reducers who worked there. For data analysis we used Interpretativism, or Interpretive Theory. The results showed that the territory of Cracolândia can present circumstances that generate diseases, but also be a place of health promotion and care.
\end{abstract}

Keywords: Health. Disease. Integral care. Crack Cocaine. Territory.

RECEBIDO EM: 25/11/2019

MODIFICAÇÕES SOLICITADAS EM: 12/8/2020

ACEITO EM: 15/10/2020

\footnotetext{
Universidade Federal de Pelotas (UFPel). Pelotas/RS, Brasil.

2 Autora correspondente. Universidade Federal de Pelotas (UFPel). R. Gomes Carneiro, 1 - Centro, 96010-610, Pelotas/RS, Brasil. http://lattes.cnpq. br/5617014399699959. https://orcid.org/0000-0001-8593-1397mila85@gmail.com
} 


\section{INTRODUÇÃO}

As políticas antidrogas tiveram suas bases no período ditatorial. 0 processo de abertura da política sobre drogas no Brasil foi lento e acompanhado de arranjos na esfera macropolítica, que permitiram que práticas autoritárias e ditatoriais se mantivessem, mesmo dentro do próprio Estado Democrático (PASSOS; SOUZA, 2011). Para esses autores, a "guerra às drogas" se forma por inúmeras razões, desde o fracasso econômico da década de 80 , o desemprego que assolava o país, o sucateamento da educação pública, a precarização da educação das crianças e jovens, o aumento da violência urbana, o crescimento das favelas e periferias, o forte tráfico de drogas e formação de facções que enfrentavam e traçavam um embate direto com a polícia, assim como o mercado de armas e o aumento da criminalidade. Neste cenário a "guerra às drogas" torna-se um exercício de controle social permeado pelo poder e violência policial e estatal (PASSOS; SOUZA, 2011).

A assistência e o tratamento para as pessoas que usam drogas no Brasil são frutos de uma mudança no modelo assistencial no país: a Reforma Psiquiátrica, que teve sua garantia com a publicação da Lei $10.216 / 2001$. A partir desta Reforma os cuidados à saúde mental, extensivo às pessoas que usam drogas, passam a ser responsabilidade também dos dispositivos da rede básica. No mesmo período foi aprovada a Política Nacional Antidrogas (Pnad), ainda com enfoque proibicionista e visando a uma sociedade livre do uso de drogas. Embora de forma contraditória, esta mesma política também apoiava a criação de estratégias de redução de danos na prevenção das doenças infectocontagiosas, mesmo que restrita somente à prevenção da doença (MACHADO; BOARINI, 2013; PACHECO, 2013).

A política nacional antidrogas não especificava o que definia como estratégias de redução de danos e também não tinha uma posição clara sobre as ações que o programa já desenvolvia. Em 2002 foi instituída a Lei no 10.409 , que priorizava o tratamento das pessoas que usam drogas, de forma multiprofissional, com o apoio da família e por meio de estratégias de redução de danos. Teve, contudo, vários de seus artigos vetados e por este motivo não revogou por completo a Lei em vigor na época, que era a 6.368/1976 (SANTOS; OLIVEIRA, 2012). Já foi possível perceber, no entanto, que uma nova consciência de cuidado às pessoas que usam drogas começava a emergir no campo da saúde pública e novas políticas se encaminhavam, mesmo que suas execuções fossem efetivadas de forma lenta.

Em 2003 o Ministério da Saúde estabeleceu a Política de Atenção Integral aos Usuários de Álcool e Outras Drogas, admitindo a existência de um atraso histórico do Sistema Único de Saúde (SUS), no que respeita às ações ao enfrentamento das questões relacionadas ao uso de drogas. Esta política já não visava mais à repressão e ao controle, era pautada em uma abordagem comprometida com o usuário, constituindo este um marco importante para o cuidado com as pessoas que usam drogas (ROMANINI; ROSO, 2012; PACHECO, 2013). É por meio desta política que o Ministério da Saúde assume o desafio do cuidado integral e articulado, enxergando os usuários dentro do âmbito da saúde pública e como pessoas que necessitam de tratamento, prevenção, promoção e proteção.

A Redução de Danos (RD), lançado por meio da Portaria № 1.028 de 2005, é uma estratégia de cuidado que parte do real para uma situação que apresente uma melhor qualidade de vida para o sujeito, a partir de suas próprias escolhas, pois é ele quem meIhor pode avaliar sua construção de vida. É o caminhar junto, no processo de subjetivação do cuidado. Em conjunto com outros saberes e tecnologias, as estratégias de Redução de Danos podem ajudar a moldar as políticas públicas e sociais, tratam de uma forma de relação com a vida ou com a ausência dela, sempre levando em conta os desejos, escolhas, demandas e sentimentos de cada indivíduo.

Foi a partir da Reforma Psiquiátrica, por intermédio da Luta Antimanicomial e do Movimento Antiproibicionista, que o conceito de comportamento de risco ou comportamento desviante atribuído à pessoa que usava drogas passou para a compreensão de um conceito de situação de vulnerabilidade, permitindo assim o olhar para outras esferas, como as questões sociais, econômicas, culturais e políticas, que poderiam determinar e influenciar o comportamento da pessoa, e não apenas o uso da substância (MACHADO; BOARINI, 2013). A depender do padrão de uso da substância e da vulnerabilidade associada ao uso do crack, pode resultar na dependência e assim acarretar danos e agravos tanto à saúde física como à saúde mental, também interferindo no contexto social do indivíduo, nas suas relações familiares e na dificuldade de acesso aos serviços de saúde (RODRIGUES et al., 2012).

O cuidado a essa população, assim como as questões que envolvem este uso, são complexos e exigem cada vez mais o aprimoramento das políticas 
públicas e a capacitação dos profissionais para acolher estas pessoas, seja no serviço ou no território. Com o incentivo à descentralização dos serviços o cuidado dos usuários passa a poder ser realizado de diversas formas e em diferentes serviços, como no Centro de Atenção Psicossocial Álcool e Drogas (Caps AD), por meio de internações breves em hospitais gerais, e com o acompanhamento pelo Programa de Redução de Danos (PRD) (FRANCHINI, 2016; MACHADO; BOARINI, 2013; PACHECO, 2013). Em 2011 ocorreu pela Portaria 3.088 a instauração da Rede de Atenção Psicossocial (Raps), por meio da qual deve ocorrer a criação, ampliação e articulação dos diversos pontos de atenção e cuidado à saúde de pessoas com sofrimento, ou transtorno mental, e com necessidades decorrentes do uso de crack, álcool e outras drogas. Constitui um dos objetivos da Raps garantir a articulação e integração dos diversos e diferentes pontos de atenção das redes de saúde no território (BRASIL, 2011).

Trabalhar no território e conhecer o fluxo é necessário para desenvolver esse cuidado em rede. Nesse sentido é importante saber que a Cracolândia, um dos primeiros locais de uso de substâncias ao ar livre, choca desde a chegada às suas adjacências, e que não é preciso adentrar o fluxo para perceber que se está na região da Luz (São Paulo/SP). A paisagem urbana muda, as pessoas na rua, os prédios e o comércio modificam-se a cada quadra, o Terminal Princesa Isabel já representa o que se esconde nas próximas quadras, o fluxo já vai logo mostrando a sua cara. Raupp e Adorno (2011) e Rui (2012) ressaltam em seus estudos que a Cracolândia em São Paulo, na então região da Luz, nasce em meados dos anos 90 , quando os primeiros relatos do uso de crack surgem na cidade, porém vão além e reforçam a ideia de uma Cracolândia como lugar que extrapola o aspecto geográfico. Segundo Rui (2012), a Cracolândia é onde as pessoas se encontram muito mais do que apenas um território delimitado.

Costa (2017) conceitua o fluxo como um aglomerado de pessoas, uma alusão ao contexto positivo de diversão e festa, pois é o nome dado aos bailes funk de rua de São Paulo. O fluxo seria o espaço menor, uma "parte" da Cracolândia, o local onde tudo acontece. Não apenas como um recorte territorial, mas o fluxo se constitui como um local de relações com e no território. É a ocupação do espaço, as trocas e relações, mais do que um espaço de concentração de pessoas, é um emaranhado de nós e infinitas interações e movimentos. Há uma infinidade de histórias, de sujeitos e de afetos circulando entre todas essas questões. Rui (2014) ressalta a importância de perceber a Cracolândia como um território heterogêneo, com múltiplos atores sociais envolvidos. Embora as pessoas que usam crack se constituam como grupos, elas não estão todas ali pelo mesmo motivo ou pelas mesmas razões e sequer consumindo a substância da mesma maneira ou mantendo a mesma relação com a droga.

A relação de cada pessoa com a substância que consome varia em razão de diferentes aspectos, como o contexto e padrão de uso, podendo acarretar níveis diferentes de prejuízos físicos, mentais e sociais (RONZANI et al., 2014). Diante das questões expostas, o presente estudo justifica-se pela necessidade de se pensar o cuidado em saúde das pessoas que usam substâncias psicoativas para além da relação entre o sujeito e a droga. É preciso conhecer a história de vida e o contexto de uso em que essas pessoas se encontram. Logo, esta pesquisa teve como objetivo compreender as questões que envolvem as condições de saúde e de doença das pessoas que usam drogas e/ ou se encontram em situação de rua no território da Cracolândia.

\section{MÉTODO}

Este artigo é parte integrante da tese de Doutorado intitulada: Entre trocos e trocas: uma etnografia das relações entre redutores de danos e pessoas que usam drogas na região central da cidade de São Paulo, e buscou compreender as questões que envolvem as condições de saúde e de doença das pessoas que usam drogas e/ou se encontram em situação de rua no território da Cracolândia. Os participantes foram pessoas que fazem uso de drogas nas cenas de uso e/ ou que frequentam o Centro de Convivência É de Lei, e os agentes redutores de danos da Organização Não Governamental (ONG) É de Lei.

Os critérios de inclusão para as pessoas que usam drogas foram: ser maior de 18 anos; ser acessado pela ONG É de Lei e fazer uso de crack. Para os agentes redutores de danos: ser maior de 18 anos; fazer parte da ONG É de Lei e se reconhecer como um redutor de danos. Os critérios de exclusão (pessoas que usam drogas e agentes redutores de danos): não permitir a gravação da entrevista e/ou apresentar dificuldades de comunicação no momento de responder à entrevista. As pessoas que fazem uso de crack foram identificadas por nomes de estrelas, como quebra de paradigma de que usuários de crack não são capazes de brilhar em sua vida, rompendo com o estigma de que o uso da substância é o fator que se sobressai em suas histórias. Os agentes redutores de danos tiveram 
seus nomes trocados por outros nomes (apelidos) não binários, garantindo o anonimato a todos os participantes da pesquisa.

Participaram das entrevistas quatro agentes redutores de danos da ONG É de Lei e três pessoas que fazem uso de drogas e frequentam a região da Cracolândia, totalizando sete entrevistas. Não foi possível quantificar os participantes da observação participante, visto que nas cenas de uso o fluxo de pessoas era muito dinâmico.

A coleta de dados teve duração de seis meses, entre março e agosto de 2018 , totalizando em média 60 dias em campo e mais de 300 horas de observação, o que resultou em 450 páginas de diários de campo. As observações ocorrem em variados horários e dias da semana, estando a pesquisadora disponível 24 horas por dia e 7 dias por semana para o trabalho de campo.

Os dados foram coletados por meio da observação participante, que ocorreu a partir da inserção de uma das pesquisadoras, a qual esteve realizando a coleta no território e elaborou o diário de campo, instrumento básico e fundamental do pesquisador. Nele foram anotados de forma pessoal todas as sensações, experiências, sentimentos, percepções e emoções sentidos e vivenciados durante as observações. Todos esses relatos foram descritos da forma mais fiel e detalhada possível, pois foi a partir dessas anotações que se construiu a análise dos dados e por este motivo foi extremamente importante manter uma ordem cronológica ao escrever o diário ou ao menos realizar um esboço com as principais ideias ao final de cada observação, para que nenhum detalhe se perdesse ou fosse esquecido pela pesquisadora (VÍCTORA; KNAUTH; HASSEN, 2001). Também foram realizadas entrevistas etnográficas com os participantes. Na percepção de Beaud e Weber (2014), a entrevista etnográfica garante ao pesquisador uma liberdade maior, pois mesmo ao ir com um roteiro preestabelecido, ao longo da conversa, ao tocar em determinados assuntos ou situações que demonstrem certa relevância, é possível omitir ou adaptar as perguntas já preparadas, replanejando no mesmo momento a entrevista e mudando a direção das questões, podendo abranger respostas que se mostrem importantes para a análise e os objetivos da pesquisa. A maioria das entrevistas foi realizada na sede da ONG É de Lei, em sala reservada, de forma livre e sem agendamento prévio; apenas uma entrevista ocorreu no próprio território da Cracolândia, em frente a um bar frequentado pelos profissionais e moradores da região. As entrevistas tiveram duração de 30 a 60 minutos entre os redutores de danos; já quanto às entrevistas com as pessoas que usam drogas, apenas uma delas teve duração superior a uma hora, as outras duas a duração foi inferior a 10 minutos. As pessoas que usam drogas demonstraram resistência na realização das entrevistas, algumas nitidamente não se sentiam à vontade com o uso do gravador ou de ficarem apenas com a pesquisadora em um local reservado.

A análise dos dados ocorreu concomitantemente ao trabalho de campo, por meio da leitura detalhada do diário de campo e das transcrições das entrevistas realizadas. Foi utilizado o Interpretativismo, ou Teoria Interpretativa, escrita por Cliffort Geertz (2008).

Após a apreciação do projeto pela equipe do Centro de Convivência É de Lei, mediante a assinatura da Carta de Anuência e da aprovação pela banca de qualificação, o projeto foi encaminhado à Plataforma Brasil para escolha do Comitê de Ética e Pesquisa (CEP) e aprovado com o número do parecer 2.446 .542 no ano de 2018. Os princípios éticos considerados para a elaboração desta tese foram ao encontro da Resolução no 466/2012 do Conselho Nacional de Saúde, do Ministério da Saúde, sobre Pesquisa com Seres Humanos. Aos participantes foi assegurado o direito de se manterem anônimos, de desistirem da pesquisa a qualquer momento, até mesmo após o término da coleta de dados e de terem os resultados obtidos apresentados após a finalização da escrita da tese. Os dados foram coletados com as pessoas que aceitaram participar da pesquisa por meio da assinatura, em duas vias, do Termo de Consentimento Livre e Esclarecido (TCLE) que foi apresentado, lido e discutido, acompanhado de cada participante.

\section{RESULTADOS E DISCUSSÃO}

A vida de muitas das pessoas que frequentam a Cracolândia é marcada pela pobreza, pela falta de acesso a serviços de saúde, à alimentação, a direitos básicos e necessários para uma vida saudável do ponto de vista físico e psicológico. Eles e elas misturam-se ao lixo, ao papel higiênico usado, a alimentos que foram rejeitados. Perante a sociedade essa população usuária de drogas é vista como grupos de pessoas que apresentam comportamentos desviantes, que não respeitam regras e não sabem viver conforme o que é imposto como certo e errado, em razão de realizarem uma atividade ilegal, como o consumo de crack, que é uma substância ilícita e proibida no país (FERREIRA, 2013). 
Camargo (2014) e Ferreira (2013) refletem sobre o quanto as pessoas que usam drogas precisam provar a todo o momento que apesar da condição de usuárias de crack, por exemplo, elas não são criminosas, deixando claro o quanto a exclusão e o estigma trazem dor e sofrimento, em virtude da humilhação e preconceito sofrido. Quando a pessoa não encontra um local, uma rede solidária e sensível para o seu acolhimento, mas ao contrário, está envolto em uma rede social que a exclui e estigmatiza, um dos resultados é a marginalização e invisibilidade desse sujeito. Há uma ruptura com o seu grupo de origem (que pode ser o grupo familiar) e uma busca por um grupo que o acolha, que o faça sentir entre os pares (Cracolândia). O território da Cracolândia vai se configurando para além de espaço geográfico, para um local de socialização, por intermédio de uma totalidade de relações e vínculos (ARRUDA, 2014).

Não se pode negar que a Cracolândia abriga as pessoas que usam drogas de forma mais abusiva, não apenas o crack, mas o álcool e tabaco também são bastante presentes dentro do fluxo. Algumas das pessoas que circulam pelo fluxo nem fazem uso de crack ou até nunca fizeram, porém ainda assim mantêm um vínculo forte com o território, não na condição de espaço físico, mas como local de produção de cuidado, relações, proteção social e trocas. Em relação a outras drogas, as pessoas que usam crack podem apresentar um padrão de consumo abusivo mais grave e consequentemente um maior envolvimento com atividades ilegais, prostituição, maiores chances de se encontrar em situação de rua e maior probabilidade para doenças e agravos a saúde (PERRENOUD; RIBEIRO, 2012).

Em contrapartida, Raupp e Adorno (2010) ressaltam que pessoas que usam crack, muitas vezes, reconhecem os aspectos negativos do consumo e os riscos associados a essa prática. Então, mesmo dentro do padrão abusivo, a pessoa pode ser capaz de identificar o tipo de relação que está estabelecendo com a substância e os danos que isso pode lhe causar. Apesar do consumo intenso, muitos deles conseguem reconhecer as práticas de redução de danos, conforme demonstrado no trecho a seguir.

Quando estávamos caminhando ouvimos uma pessoa atrás da gente nos chamar, viramos para trás, era um rapaz que estava comendo uma marmita, ele perguntou o que tínhamos para oferecer que reduzisse os danos para ele (provavelmente ele leu nossa camiseta atrás que diz: Agente Redutor de Danos). Falamos sobre os insumos e entregamos piteiras, manteiga de cacau e preservativos. Essa abordagem faz refle- tir o quanto eles também procuram estratégias para o cuidado (Diário de Campo - Cracolândia 19/7/2018).

O trecho a seguir também reforça, além da questão do lado de dentro e de fora, nós (É de Lei) sendo as pessoas que se dispõem a estar do lado de dentro, a importância que isso tem para as pessoas que usam drogas e que estão diariamente no fluxo, moram do lado de dentro, não querem mais fazer parte do lado de fora.

A reflexão segue na perspectiva de quem está do lado do fluxo ou não. A polícia, por exemplo, é vista como a força que está totalmente do lado contrário, tanto que ela se mantém do lado de fora, na beirada, como contenção para que o fluxo não ultrapasse as barreiras que não lhes são permitidas. Os redutores, em contrapartida, estão ali para cuidar e acolher e isso os tornam parte de dentro, do mesmo lado dos usuários. Essa relação é muito forte e nos traz muitos dados sobre as trocas existentes no território e entre todos os atores sociais lá envolvidos. Os redutores estão ali para ir além de estratégias de redução do consumo de drogas, mas como garantia de direitos humanos, garantia de acesso à informação e à qualidade de vida. Os usuários reconhecem os redutores como pessoas que vão ali ajudá-los, é unânime que todos nos reconhecem como pessoas que estão do mesmo lado que eles, não do lado contrário. O É de Lei é sempre bem recebido no fluxo e os usuários se mostram extremamente agradecidos pela presença dos redutores - não por serem redutores, mas por serem pessoas que se propõem a ir até lá, dentro do território (Diário de Campo - Cracolândia 20/4/2018).

Quando estamos a falar sobre vida, sobre pessoas, é imprescindível lidar com as singularidades e as diferentes demandas e necessidades de cada uma. É necessário conhecer o território e as pessoas, traçar junto a elas estratégias para o cuidado de sua saúde e todas as outras questões que as envolvem, não visando apenas a um tratamento, mas um autocuidado e autoconhecimento (BASTOS; ALBERTI, 2018). Vaz (2015) reforça a importância de incluir os próprios sujeitos na condição de força coletiva do processo de construção do cuidado e das políticas públicas voltadas as suas demandas e necessidades.

No entendimento de Rui (2012), para analisar o que move, empolga, toca e afeta as pessoas, não é preciso necessariamente conhecer toda a sua história de vida. É importante, sim, ter um olhar humanizado e fora dos estereótipos impostos pela sociedade. As relações se estabelecem a partir da presença, ela ga- 
rante o vínculo. A presença no território, do lado de dentro, é fundamental para o fortalecimento das teias que permeiam todo esse contexto social e cultural que está presente no campo.

A interação entre os frequentadores da Cracolândia e os outros atores sociais, seja institucional ou não, é variada e multifacetada, englobando diversos aspectos que influenciam nesse processo (ADORNO et al., 2013). A seguir um trecho que traz a presença da $\mathrm{Ca}$, ex trabalhadora do território, que atuava na assistência social na antiga gestão municipal e agora segue realizando trabalhos e atividades no fluxo de forma voluntária. A observação também ressalta a importância dessas atividades e o quanto favorecem o autocuidado e autoestima das pessoas que usam drogas e se encontram em situação de rua na região. Em contrapartida a presença da força policial está sempre colocando em risco as ações voltadas ao cuidado e acoIhimento dos usuários, como se fosse um prazer para eles (polícia) que nada desse certo a favor do fluxo.

Todos os sábados em frente ao Memorial da Resistência, na Praça General Osório, Ca realiza uma feira e um brechó para mulheres e transexuais. Hoje ela realizou uma ação de autocuidado dentro do fluxo, na Helvétia. Além de oficinas de corte, penteado, manicure e maquiagem, também havia um brechó com roupas femininas. Havia um fotógrafo voluntário registrando a atividade e Elias, da A Craco Resiste, também esteve presente durante a ação. Nós do É de Lei ficamos ao lado com a nossa mesa e realizando as atividades de sempre, entrega de insumos, água e diálogo sobre redução de danos e cuidado. Ca chegou cheia de malas e com algumas pessoas que iriam ajudá-la e mais algumas pessoas do próprio fluxo que estavam ajudando a pegar mesas e cadeiras. Em poucos minutos tudo estava montado na frente da Igreja Bola de Neve. O pessoal da Igreja (dois rapazes) ficou o tempo todo junto conosco. Durante a ação de autocuidado, algumas mulheres ao saírem maquiadas e arrumadas, já falavam que hoje não iam ficar na Cracolândia, que iriam passear. Isso mostra o quanto essas pessoas são carentes de autoestima e cuidado, o que as coloca cada vez mais nessa condição de vulnerabilidade. Muitas delas ficavam longos minutos fazendo poses e poses para foto, realmente se sentindo verdadeiras modelos. Essas são cenas que ao final de um dia como esse não têm preço e valem todo o tempo passado no território. Alguns usuários deixaram o seu nome na fila e depois, quando a polícia fechou a rua para a limpeza, eles me gritavam de dentro do fluxo para saber se já era a hora deles. Isso foi bem interessante, pois mesmo dentro do fluxo e consumindo a droga eles se lembravam que tinham ficado na lista do corte e estavam preocupados com isso. Mesmo agitados eles esperaram a limpeza terminar e nós seguimos a atividade com quem estivesse ali. Muitos do outro lado do fluxo seguiam me fazendo sinal, preocupados em perder a oportunidade de cortar o cabelo. Isso foi me deixando bem chateada também. Não custava nada os policiais liberarem eles, porém nada ali funciona para o bem do fluxo, nada (Diário de Campo - Cracolândia 17/5/2018).

Outro fator importante observado por alguns pesquisadores é que mesmo sem o mínimo de serviço sanitário no local, como banheiros, local para tomar banho ou lavar seus pertences ou roupas, muitos usuários driblam suas adversidades e conseguem encontrar estratégias para manter boas condições de aparência e higiene, como cortar a barba ou o cabelo até mesmo na própria rua (GOMES; ADORNO, 2011; ADORNO et al., 2013). Essas questões mais uma vez contrariam o senso comum e a imagem que a mídia passa de todos os usuários de crack viverem em situação deplorável e beirando à morte, pois, até em locais de uso como a Cracolândia, encontram-se pessoas que mesmo fazendo uso de drogas, também se preocupam com sua aparência física, sua alimentação e sua saúde. $O$ resultado da observação sobre a oficina de autocuidado da Ca mostra realmente o que os autores vêm apresentando, que a realidade do fluxo e dos usuários não é somente de miséria, pobreza e sujeira. Há também aqueles que se preocupam com a aparência, que cuidam de si. Essas ações de autocuidado ajudam fortemente nesse processo, encorajando e impulsionando as estratégias de redução de danos e cuidado da população presente no território.

O acesso aos serviços de saúde, no entanto, é muito difícil. Pesquisa realizada pela Fundação Oswaldo Cruz em 2013 mostra que 78,9\% das pessoas entrevistadas (usuárias de drogas) afirmaram ter interesse em buscar tratamento, porém apenas $6,3 \%$ revelaram ter recebido atendimento nos Caps $A D$, serviço que a priori seria específico para a demanda desta população (FIOCRUZ, 2013). O acesso à saúde, portanto, mesmo sendo um direito assegurado pelo artigo 196 da Constituição Federal, de caráter universal e garantido a toda a população, ainda encontra obstáculos a serem enfrentados (FRANCHINI, 2016; GOMES; ADORNO, 2011). Calil e Costa (2015) também reforçam o quanto uma parcela considerável da população que faz uso de drogas já tentou acessar algum serviço da rede públi- 
ca e não foi acolhida, devido a sua condição e padrão de consumo e em especial pela precariedade de alguns serviços.

Andrade (2011) reflete sobre o fato de as pessoas que usam drogas ficarem cada vez mais marcadas pela falta de vínculos institucionais, desde a família, a escola, até a falta de acesso aos serviços de saúde. Muitos são os fatores para que isso aconteça e para compreender essa situação é necessário olhar além da ideia preconceituosa que o senso comum e a mídia impõem diariamente em relação às pessoas usuárias de drogas, como desleixadas ou que não procuram atendimento porque não querem. É necessário pensar que muitas vezes a pessoa que usou crack durante toda a noite ou a profissional do sexo que trabalhou a madrugada inteira dificilmente chegará nas primeiras horas da manhã, sem dormir ou ainda sob o efeito de alguma substância, à espera de atendimento em uma Unidade Básica de Saúde (UBS), sabendo que ainda corre grandes riscos de ser discriminada e estigmatizada, além de muitas vezes nem dispor de dinheiro para uma passagem de ônibus para se deslocar até o local, por exemplo.

$\mathrm{Na}$ fala a seguir Ka, um redutor de danos que fez parte da pesquisa, mostra o quanto as questões que envolvem o consumo de drogas vão além do próprio uso, são questões relacionadas à pobreza, vulnerabilidade, falta de acesso aos serviços, estigma, relações familiares e sociais fragilizadas. Há todo um contexto social, cultural e emocional que permeia esse uso abusivo. Muitas vezes esses fatores externos foram os causadores do abuso de drogas e não o consumo que levou a pessoa a tais situações.

Além da desconstrução de tantos preconceitos, acho que mais importante para mim foi observar a complicação maior a respeito do que a Redução de Danos foi me apontando ao longo do trabaIho, que é: os problemas geralmente associados ao uso compulsivo de substâncias, empiricamente, na prática, se mostrou serem problemas que as pessoas enfrentam por estarem em condições de marginalidade, violência e sofrimento. O uso de substâncias estava mais relacionado com o alívio desse sofrimento do que de fato causando ele (Entrevista - Ka).

Vieira et al. (2010) e Almeida (2010) ressaltam que as pessoas que usam drogas são constantemente estigmatizadas e excluídas do convívio social. Os autores seguem reforçando que os serviços de saúde devem estar disponíveis para realizar a inserção destas pessoas na sociedade, assim como propiciar uma meIhor qualidade de vida, visando consequentemente à efetivação dos direitos destes sujeitos como cidadãos que são (VIEIRA et al., 2010). Rui (2012) completa que muitas vezes os próprios serviços não conhecem uns aos outros. A autora relata cenas próximas do que também se observou na presente pesquisa, dos profissionais se esbarrarem no território e só assim conversarem e conhecerem o serviço do colega, pois a desarticulação entre a rede é gritante. Rui (2012) ainda reflete que os embates internos e externos entre as Secretarias de Saúde e de Segurança, assim como a autonomia das profissões, das atribuições policiais e as incumbências médicas são visíveis nas questões que envolvem o consumo de crack e as medidas para o cuidado da população usuária.

Por se tratar de um desafio tão complexo trabaIhar com a temática do uso de drogas e especialmente, a partir das demandas e singularidades de cada sujeito, torna-se fundamental articular diversos tipos de saberes, abrangendo as questões de cunho psicológico, sociológico, jurídico, religioso e tantos outros saberes e práticas já presentes no território, mas que atuam desarticulados e desassociados uns dos outros. Mediante um trabalho em conjunto é mais fácil oferecer soluções e estratégias que reverberam diretamente na qualidade de vida do usuário, respeitando o seu espaço, escolhas e trajetória. A perspectiva interdisciplinar garante o cuidado humanizado e integral, além de ações articuladas e sem a pretensão de um saber único ou poder em uma única área (CONTE et al., 2004).

Corroborando a importância dos serviços de saúde em conseguir realizar um cuidado humanizado, Ronzani et al. (2014) discorrem sobre o preconceito, discriminação e estigma aos usuários como uma barreira importante para o tratamento. Para além das abordagens técnicas de cuidado, a esfera da relação entre profissional e usuário aparece como um fator fundamental para o cuidado adequado. O tratamento que deve ser dispensado a essa população deve ocorrer em liberdade, dando opção aos sujeitos de escoIherem sobre o que desejam para sua vida. É necessário um olhar minucioso e mais complexo no que diz respeito ao cuidado às pessoas que usam drogas, em consonância com a Reforma Psiquiátrica e priorizando o reconhecimento dos usuários como cidadãos de direito (GRANJA, 2011; CRUZ, 2012).

Diante desse contexto, é importante avaliar o consumo de drogas e as pessoas que fazem uso delas em uma relação complexa, na qual a dimensão humana precisa ser considerada. Ou seja, é a forma como a pessoa se relaciona com a droga que deve ser levada em conta e não a droga em si. Muitos usuários 
perdem a oportunidade de ter acesso a um cuidado adequado por serem vítimas de preconceito e estigmatização nos serviços de saúde. Para reverter esta situação é preciso haver uma mudança de postura por parte dos profissionais (RONZANI et al., 2014). A sociedade julga de forma generalizada todos que usam drogas, mais especificamente o crack, como pessoas perigosas e marginalizadas. Isso produz de forma injusta marcas decisivas e muitas vezes permanentes na vida desses sujeitos, por meio de um diagnóstico baseado em uma moralidade e um juízo de valor carregado de preconceito e estigma. Para que haja uma mudança nesse pensamento, é de extrema importância o trabalho dos profissionais da saúde. É necessário o compromisso de olhar para os usuários como pessoas, valorizando suas potencialidades, retirando o olhar julgador e mostrando à sociedade e à própria pessoa que usa drogas que há variadas formas de cuidado (BARD et al., 2016.

Os dois trechos a seguir, o primeiro retirado da entrevista com um usuário e o segundo fruto das observações do diário de campo, reforçam a importância do É de Lei para o cuidado das pessoas que usam drogas e também a importância da presença física dos redutores no território, fortalecendo o vínculo, favorecendo o acesso aos serviços, garantindo a proteção dos direitos humanos e especialmente compartilhando as estratégias de reeducação de danos.

Essa percepção que eu saquei no É de Lei, de como os profissionais eram muito preparados para o debate mesmo. Me chamou a atenção também, além da sensibilidade, a capacidade de diálogo e de escuta e o preparo que, aí isso eu fui vendo ao longo dos meus encontros no É de Lei, o preparo intelectual da galera mesmo, além da sensibilidade a galera estuda, se dedica, saca? Eu passei a participar muito dos encontros assim, sobretudo o Chá de Lírio, porque eu achava legal sempre, nunca perdi essa posição de ir num debate e ficar aprendendo e ouvindo, de eventualmente intervir, mas basicamente ouvir assim. Então essa é minha relação com o É de Lei. Ela foi gradualmente ficando mais íntima, mais forte, foi criando mais vínculos também (Entrevista - Alcor).

A postura dos redutores é um grande facilitador para as relações, essa troca de perto, olho no olho, só favorece e fortalece a confiança entre eles. Um usuário se aproximou e sentou na nossa frente, antes de fumar ele nos olhou e disse: vim pedir um cachimbo na frente da saúde. Eu e Rô falamos que não tinha problema nenhum, mas que seria legal se ele usasse a piteira. Rô ra- pidamente pegou uma piteira com Ju e agachou perto dele, explicando como usar e quais seriam os danos reduzidos. Ele colocou a piteira no cachimbo e demonstrou ter aprovado a estratégia. Essa relação de cuidado que os redutores têm com os usuários faz uma diferença enorme na vida dessas pessoas. No momento em que ele chega pensando que será advertido por nós pelo uso, ele recebe um insumo para que possa se cuidar. Rô não deixou passar uma oportunidade de cuidado, consegue perceber as necessidades e atender essas demandas (Diário de Campo Cracolândia 17/7/2018).

É necessário compreender o contexto de vida dessas pessoas e seus comportamentos diante do uso de drogas. Para tanto a observação destes sujeitos no território e de como eles se relacionam com a cultura e com as demais pessoas que circulam no local foi fundamental para esta pesquisa. O contexto individual e coletivo é de extrema importância, pois o uso da substância em si não pode ser considerado de forma isolada. Muitas vezes essas pessoas tiveram poucas chances e/ou possibilidades na vida, não tiveram laços familiares e cresceram em orfanatos ou na rua. Tiveram pouca escolaridade, desde novos já iniciaram passagens pelo sistema carcerário e têm suas trajetórias de vida marcadas pela exclusão e invisibilidade social, antes mesmo de terem iniciado o consumo de alguma substância (GOMES; ADORNO, 2011). Seguindo nesta discussão, os autores Elias e Bastos (2011) e Almeida (2010) observam que as pessoas que usam drogas são desrespeitadas e responsabilizadas por todas as situações de criminalidade, violência e insegurança que acontecem, sendo sempre tratadas como sujeitos que não merecem estar no convívio social.

Para Elias e Bastos (2011, p. 4.722) "Os usuários de drogas ilícitas constituem um segmento posto à parte dos direitos de cidadania conquistados pela sociedade". Para que se possa chegar a um novo sentido no cuidado das pessoas que usam drogas é preciso romper com o abandono e isolamento arquitetado socialmente para essa população. Isso se faz com expressões de troca de cuidado e reintegração social, por meio do resgate de uma relação próxima e acolhedora (EICHELBERGER, 2012).

Colocando-nos do lado de dentro, oferecendo cuidado e saúde, fazendo circular o afeto, as experiências, as trocas, estamos produzindo vida. A proximidade e a presença do lado de dentro garante essa construção. $O$ vínculo favorece o cuidado, posto que além de ser fundamental para a constituição de vias menos dolorosas durante a fase de algum sofrimento, ele resulta numa melhor qualidade de vida, cria laços 
afetivos e age diretamente na autoestima (SILVEIRA; D'TÔLIS, 2016). Os processos de cuidado e de existência estão em constante movimento, em fluxo contínuo. Isso oferece a possibilidade de transformação e de novas experiências. O vínculo é fundamental na medida que é necessário pensar, conhecer e se aproximar para melhorar a qualidade de vida e saúde das pessoas atendidas.

O movimento da Redução de Danos opera como tensor, amplia os territórios, sustenta outras possibilidades de cuidado que não são capturadas por outras esferas. Eichelberger (2012, p. 52) segue a sua reflexão e argumenta que "reduzir danos consiste, então, em ampliar conexões nesses territórios, ampliando as associações comuns que tornam possível ativar processos de comunicação coletiva e restaurar suas redes de vida". A RD, para a autora, valoriza o espaço em que as relações se encontram, dá valor à vida e suas potencialidades, não necessariamente focando na questão do consumo, mas em todas as questões que envolvem o sujeito, como afirma na citação a seguir: "...escapando dos enfoques na droga que interditam territórios de vida e tanto comprometem as práticas de cuidado" (p. 32). Ou seja, a RD trabalha focada no acesso à construção e reconstrução das redes de vida e produção de saúde, não exclusivamente no uso que o sujeito faz da substância, mas nas outras possibilidades de cuidado existentes.

Fazer Redução de Danos vai além das questões do sujeito, é a transformação da sociedade e a forma como ela lida e reverbera com o uso e os usuários e vice-versa. É preciso refletir sobre a importância de olhar as múltiplas possibilidades das diferentes coisas em seus contextos. A RD permeia as trocas e as relações, serve como um aporte, um conjunto de procedimentos, uma perspectiva de cuidado e de ética dirigida às pessoas que usam drogas (COSTA, 2017). A proximidade que os redutores conseguem manter com o fluxo é fruto do acolhimento e do cuidado livre de julgamentos e imposições. Diferentemente de muitos outros serviços de saúde, os redutores ao adentrarem o fluxo ou ao abrirem o espaço de convivência, em ambos os casos estão do lado de dentro, do lado das pessoas que usam drogas e isso fortalece e mantém a relação de afeto e respeito entre eles (SANTOS; SOARES; CAMPOS, 2010; SANTOS; MATTOS; FREI, 2014; FORTESKI; FARIA, 2013; PASSOS; SOUZA, 2011; SOUZA; MONTEIRO, 2011; ELIAS; BASTOS, 2011; FONSÊCA, 2012). A RD caminha ao contrário da criminalização e patologização dessa população, oferecendo a ela uma gama de possibilidades fora do estereótipo de criminosos e doentes (PASSOS; SOUZA, 2011).
O trabalho do redutor de danos possibilita também um diálogo com os outros profissionais da rede, para que estes também adotem uma postura de respeito, proximidade e cuidado. Isto facilita que a pessoa se sinta efetivamente acolhida pelo serviço; assim sendo, o trabalho do redutor leva a uma maior adesão do sujeito ao tratamento e ao serviço, por intermédio de práticas humanizadas. O resultado é a diminuição da marginalização e estigmatização das pessoas que usam drogas pelos serviços de saúde e até mesmo pela sociedade (SILVEIRA; D'TÔLIS, 2016). O trecho a seguir corrobora, a medida que confirma, por meio da perspectiva durante as observações, que o papel que os redutores assumem em campo facilita o acesso ao cuidado e a outros serviços de saúde.

É a confiança que os usuários têm na equipe que possibilita essa interação. O papel do redutor no território possibilita ouvir, conhecer e auxiliar nas demandas daqueles que não procuram os serviços tradicionais. A Cracolândia tem também o diferencial de ter muitos serviços presentes no território. Sempre vejo equipes da assistência social, consultório na rua, CAPS i, médicos. O fluxo não está totalmente desamparado. Só que pouco eu vejo a população acessar esses profissionais, que ficam nas esquinas, observando apenas. Já os redutores do É de Lei interagem, ficam dentro do fluxo, chegam perto, conversam e isso acaba sendo uma abertura, uma porta de entrada para que o fluxo se sinta à vontade para expor seus problemas e anseios. Com isso o papel do redutor se torna essencial em campo, pois ele pode ser o único elo entre aquelas pessoas e os serviços (Diário de Campo - Cracolândia 7/6/2018).

Os agentes redutores de danos atuam de diversas formas, tanto fornecendo informações sobre a saúde da população aos serviços, ajudando na ampliação do acesso do indivíduo à rede, o acolhendo e acompanhando ao longo do tempo, realizando um cuidado integral, por meio da construção do Projeto Terapêutico Singular (PTS), em conjunto com a própria pessoa e respeitando sua autonomia e liberdade (SILVEIRA; D'TÔLIS, 2016; SOUZA; MONTEIRO, 2011). Essa atuação ocorre, especialmente, pela escuta, como apresentado na fala do redutor Bê a seguir.

Como parte desse trabalho de redutor de danos, pra além de todas as premissas que a gente vai observar, que é a autonomia das pessoas, eu procuro executar esse trabalho utilizando bastante a escuta, principalmente a escuta de verdade e como forma de estabelecer vínculo. Eu fui percebendo que era importante que eu deixasse as falas acontecerem sem querer cortar e fui aprimo- 
rando esse trabalho de escuta. Internamente não tenho método, assim, não sei como eu fiz esse trabalho de aprimoramento da escuta, a não ser escutando. Fui percebendo que essas coisas conversavam muito com a perspectiva que eu tinha de vida e aí depois eu fui conseguindo pensar em intervenções. E não em toda situação, porque tem situações que cabem intervenção e tem situações que sobra pouco espaço pra isso. Acho que hoje, assim, meu trabalho como redutor de danos, mais do que qualquer coisa é ter esse trabalho da escuta (Entrevista - Bê).

O pequeno trecho da observação a seguir também reforça a capacidade de escuta dos redutores como aliada no processo de criação de vínculos, fortalecendo as trocas e as relações que são constantemente tecidas entre eles.

Observo o quanto a escuta é um acolhimento potente e que aproxima as pessoas que usam drogas e redutores, criando um clima de confiança e de afeto mesmo entre aqueles que até então não se conheciam (Diário de Campo - Glicério 19/6/2018).

O cuidado e atenção ofertados às pessoas que usam drogas apresentam suas próprias características devido às demandas sociais específicas destes grupos. Por este motivo são tão importantes a escuta e o conhecimento das necessidades reais de cada sujeito que compõe o processo de acolhimento e cuidado. As ações voltadas a este público objetivam uma redução de possíveis riscos e danos e visam à reinserção destas pessoas em sua rede social e familiar, pensando em uma melhor qualidade de vida, a fim de combater a exclusão social e defender a tolerância e respeito às diversidades de comportamento (FORTESKI; FARIA, 2013). Quando, porém, se inclui os envolvidos no contexto das ações, as estratégias propostas evidentemente surtirão efeitos mais positivos, visto que estarão considerando as características e especificidades de cada sujeito envolvido no processo, priorizando seu contexto social/cultural e sua realidade. É nesta perspectiva que caminha a RD (SOUZA; MONTEIRO, 2011).

Mediante uma ética de cuidado, baseada nas estratégias de Redução de Danos, é possível pensar nas questões de promoção de saúde e diminuição de agravos e doenças, até mesmo em territórios das cidades considerados sem vida e doentes, como a região da Cracolândia. Realizar uma etnografia neste espaço da cidade de São Paulo, que é constantemente alvo de violência policial e de negligência estatal, trouxe à tona uma outra face, diferente daquela divulgada na mídia. Há pobreza, falta de acesso a condições básicas de saúde, educação e assistência social, mas há também vida e cuidado. Por meio da atenção integral às pessoas que usam drogas e se encontram em espaços estigmatizados de nossas cidades, podemos oferecer saúde e melhores condições de vida. É necessário pensar e agir de forma diferente, com um olhar humanizado e visando a produzir saúde por intermédio do cuidado.

\section{CONSIDERAÇÕES FINAIS}

Os resultados desta pesquisa elucidaram que estar no território da Cracolândia pode ocasionar o desenvolvimento de doenças, devido à falta de direitos básicos de sobrevivência, como alimento e água, pelo uso abusivo de drogas, pela prostituição e o escasso acesso aos serviços de saúde. Este mesmo espaço territorial, no entanto, é capaz de produzir saúde, cuidado, autocuidado. A Cracolândia é um local de trocas, de relações, de inclusão e onde se previne doenças e promove saúde. Dessa perspectiva, o presente estudo atingiu seu objetivo ao levantar as questões que envolvem as condições de saúde e de doença das pessoas que usam drogas e/ou se encontram em situação de rua no território da Cracolândia, mostrando que este é um espaço com circunstâncias adoecedoras, mas, também, um local onde é possível haver promoção da saúde e vida, a partir do cuidado e das práticas de redução de danos.

O trabalho vivo, em campo, produz vida, reproduz afetos, traz outras possibilidades de vida e de coletividade. Nossas relações são atravessadas pelo coletivo, nesse espaço circulam as trocas. A relação de trocas resulta no acolhimento, na produção de diferentes possibilidades de vida, no respeito a diferentes estilos de vida. A política de subjetividade deve ser comprometida com a ética do cuidado e o respeito às diferenças e escolhas do sujeito. A redução de danos é permeada por relações, que ao criar uma zona de trocas, impulsiona uma produção de cuidado horizontal.

Em relação ao consumo da substância, o crack não dá sono, frio, calor, sede ou vontade de ir ao banheiro. Essas questões para quem se encontra em situação de rua ou vivendo, permanecendo nas cenas de uso, é muito vantajosa, devido à dinâmica de sobrevivência do local. A saúde mental é uma das grandes questões que devem ser discutidas e analisadas entre as pessoas que usam drogas, assim como a falta de acolhimento, a dificuldade de acesso aos serviços e de outros espaços de convivência. O problema da pobreza e da marginalização dos sujeitos da Cracolân- 
dia não é justificado pelo consumo de crack, mas pelo agravamento da questão social e a inadequação das políticas públicas.

Os serviços de saúde, assistência, educação, moradia, parecem não estar preparados para acolher as pessoas em condições de exclusão social e abuso de drogas, fragilizando ainda mais as condições de vida e de re(existir) desses sujeitos. Os redutores de danos colocam-se como figuras potentes nesse elo entre usuários e outros profissionais da rede.

O machismo e assédio foram fortes limitadores durante a coleta de dados, colocando a pesquisadora que estava em campo por diversas vezes em alerta e sofrimento. A complexidade da pesquisa e dos cenários em que ela ocorreu dificultou também a realização de mais entrevistas. As escritas cronológicas e diárias do diário de campo, assim como outros obstáculos enfrentados, causaram esgotamento e saturação do campo, devido à intensidade da imersão etnográfica. A violência policial foi uma das questões mais impactantes, que tornou a pesquisa mais pesada e sofrida.

A Redução de Danos ocupa um local de trincheira, de linha de resistência e proteção das pessoas que usam drogas e diariamente encontram-se envoltas à violência policial e falta de políticas públicas e humanização. Todas essas questões reverberaram diretamente na vida dos participantes, assim como na das pesquisadoras, pois estar do lado de dentro é escolher um lado, lutar pela igualdade e pelo cuidado.

\section{REFERÊNCIAS}

ADORNO, R. C. F. et al. Etnografia da Cracolândia: notas sobre uma pesquisa em território urbano. Saúde \& Transformação Social, Florianópolis, v. 4, n. 2, p. 4-13, 2013.

ALMEIDA, R. B. F. de A. O caminho das pedras: conhecendo melhor os usuários de crack do munícipio de Recife - PE. 2010. 153 f. Dissertação (Mestrado em Psicologia Clínica) Programa de Pós-Graduação em Psicologia Clínica, Universidade Católica de Pernambuco, Recife, 2010.

ANDRADE, T. M. de. Reflexões sobre Políticas de Drogas no Brasil. Ciência \& Saúde Coletiva, Rio de Janeiro, v. 16, n. 12, p. 4.665-4.674, 2011.

ARRUDA, M. S. B. A Cracolândia muito além do crack. 2014. 168f. Dissertação (Mestrado em Ciências) - Programa de Pós-Graduação em Enfermagem, Universidade de São Paulo, São Paulo, 2014.

BARD, N. D. et.al. Estigma e preconceito: vivência dos usuários de crack. Revista Latino Americana de Enfermagem, São Paulo, v. 24, p. 1-7, 2016.

BASTOS, A. D. de A.; ALBERTI, S. Crack! A Redução de danos parou, ou foi a pulsão da morte? Psicologia USP, São Paulo, v. 29, n. 2, p. 212-225, 2018.
BEAUD, S.; WEBER, F. Guia para a pesquisa de campo: produzir e analisar dados etnográficos. 2. ed. Petrópolis, RJ: Vozes, 2014.

BRASIL. Ministério da Saúde. Portaria no 1.028, de 10 de juIho de 2005. Brasília, 2005.

BRASIL. Ministério da Saúde. Portaria no 3.088, de 23 de dezembro de 2011. Brasília, 2011.

BRASIL. Fiocruz. Ministério da Saúde. Secretaria Nacional de Políticas sobre Drogas. 2013. Perfil dos usuários de crack e/ou similares no Brasil. Brasília, 2013.

CALIL, T. G.; COSTA, R. M. O trabalho de campo do Centro de Convivência É de Lei. In: CENTRO DE CONVIVÊNCIA É DE LEI. Cultura, juventudes e redução de danos. São Paulo: Córrego, 2015. p. 17-39.

CAMARGO, P. de O. A visão da mulher usuária de cocaína crack sobre a experiência da maternidade: vivência entre mãe e filho. 2014. 121 f. Dissertação (Mestrado em Enfermagem) - Programa de Pós-Graduação em Enfermagem, Universidade Federal de Pelotas, Pelotas, 2014.

CONTE, M. et al. Redução de danos e saúde mental na perspectiva da atenção básica. Boletim da Saúde, Porto Alegre, v. 18, n. 1, p. 59-77, 2004.

COSTA, R. Mil Fitas na Cracolândia: Amanhã é Domingo e a Craco Resiste. 2017. 290f. Dissertação (Mestrado em Filosofia) - Programa de Pós-Graduação Cultura e Identidades Brasileiras, Universidade de São Paulo, São Paulo, 2017.

COSTA, R. M.; CALIL, T. G. O Trabalho de campo - experiências do É de Lei na Cracolândia. In: GODOY, Aline et al. Fórum Estadual de Redução de Danos de São Paulo. São Paulo: Córrego, 2014. p. 61-73.

CRUZ, V. D. Vivências de mulheres que consomem crack em Pelotas-RS. 2012. 112 f. Dissertação (Mestrado em Enfermagem) - Programa de Pós-Graduação em Enfermagem, Universidade Federal de Pelotas, Pelotas, 2012.

EICHELBERGER, M. O que pode a Redução de Danos? Videz-vous de tous vos clichés: o graffiti como produção de saúde. 2012. 75 f. Dissertação (Mestrado em Saúde Coletiva) - Programa de Pós-Graduação em Saúde Coletiva, Universidade Estadual de Campinas, Campinas, 2012

ELIAS, L. de A.; BASTOS, F. I. Saúde pública, Redução de Danos e a Prevenção das Infecções de Transmissão Sexual e Sanguínea: revisão dos principais conceitos e sua implementação no Brasil. Ciência \& Saúde Coletiva, Rio de Janeiro, v. 16, n. 12, p. 4.721-4.730, 2011.

FERREIRA, R. Z. O sentido antropológico de dons e dádivas entre grupos de usuários de crack e outras drogas. 2013. 102 f. Dissertação (Mestrado em Enfermagem) - Programa de Pós-Graduação em Enfermagem, Universidade Federal de Pelotas, Pelotas, 2012.

FONSÊCA, C. J. B. da. Conhecendo a redução de danos enquanto uma proposta ética. Psicologia \& Saberes, Maceió, v. 1, n. 1, p. 11-36, 2012.

FORTESKI, R.; FARIA, J. G. de. Estratégias de redução de danos: um exercício de equidade e cidadania na atenção a usuários de drogas. Revista de Saúde Pública, Florianópolis, v. 6, n. 2, p. 78-91, 2013. 
FRANCHINI, B. Experiências de pessoas usuárias de substâncias psicoativas nos serviços de saúde em um município na fronteira entre Brasil e Uruguai. 2016. 113 f. Tese (Doutorado em Enfermagem) - Programa de Pós-Graduação em Enfermagem, Universidade Federal de Pelotas, Pelotas, 2016.

GEERTZ, C. A interpretação das culturas. Rio de Janeiro: LTC, 2008. $224 \mathrm{p}$.

GOMES, B. R; ADORNO, R. de C. F. Torna-se "nóia": Trajetória e sofrimento social nos "usos de crack" no centro de São Paulo. Etnográfica, Lisboa, v. 15, n. 3, p. 569-586, 2011.

GRANJA, E. Crack, pânico social e desafios atuais. In: MORAES, M.; CASTRO, R.; PETUCO, D. Gênero e drogas: contribuições para uma atenção integral a saúde. Recife, $P E$, Instituto Papai; Gemal; Ufpe, 2011. p. 59-62.

MACHADO, L. V.; BOARINI, M. L. Políticas sobre drogas no Brasil: a estratégia de redução de danos. Psicol. Cienc. Prof., Brasília, v. 33, n. 3, p. 580-595, 2013.

PACHECO, M. E. A. G. Política de redução de danos a usuários de substâncias psicoativas: práticas terapêuticas no projeto consultório de rua em Fortaleza, Ceará. 2013. 143 f. Dissertação (Mestrado Acadêmico em Políticas Públicas e Sociedade - MAPPS) - Centro de Estudos Sociais Aplicados e Centro de Humanidades, Universidade Estadual do Ceará, Fortaleza, 2013.

PASSOS, E. H; SOUZA, T. P. Redução de danos e saúde pública: construções alternativas à política global de "guerra às drogas". Psicologia \& Sociedade, Florianópolis, v. 23, n. 1, p. 154-162, 2011.

PERRENOUD, L. O.; RIBEIRO, M. Histórico do consumo de crack no Brasil e no mundo. In: RIBEIRO, M.; LARANJEIRA, Ronaldo. O Tratamento do usuário de crack. Porto Alegre: Artmed, 2012. p. 65-75.

RAUPP, L.; ADORNO, R. de C. F. Uso de crack na cidade de São Paulo/Brasil. Revista Toxicodependências, Lisboa, v. 16, n. 2, p. 29-37, 2010.

RAUPP, L.; ADORNO, R.de C. F. Circuitos de uso de crack na região central da cidade de São Paulo (SP, Brasil). Ciência \& Saúde Coletiva, Rio de Janeiro, v. 16, n. 5, p. 2613-2622, 2011.

RODRIGUES, D. S. et al. Conhecimentos produzidos acerca do crack: uma incursão nas dissertações e teses brasileiras. Ciência \& Saúde Coletiva, Rio de Janeiro, v. 17, n. 5, p. 1.247-1.258, 2012.

ROMANINI, M.; ROSO, A. Mídia e crack: promovendo saúde ou reforçando relações de demonização? Psicologia Ciência e Profissão, Brasília, v. 32, n. 1, p. 82-97, 2012.

RONZANI, Telmo Mota et.al. Reduzindo o estigma entre usuários de drogas: guia para profissionais e gestores. Juiz de Fora: Editora UFJF, 2014. 24 p.

RUI, T. Vigiar e cuidar: notas sobre a atuação estatal na "cracolândia". Revista Brasileira de Segurança Pública, São Paulo, v. 6, n. 2, p. 336-351, 2012.

RUI, T. Usos da "Luz" e da "cracolândia": etnografia de práticas espaciais. Saúde e Sociedade, São Paulo, v. 23, n. 1, p. 61-74, 2014.
SANTOS, J. A. T; OLIVEIRA, M. L. F de. Políticas públicas sobre álcool e outras drogas: breve resgate histórico. Journal of Nursing and Health (Jonah), Pelotas, v. 1, n. 2, p. 82-93, 2012.

SANTOS, V. E dos; SOARES, C. B.; CAMPOS, C. M. S. Redução de danos: análise das concepções que orientam as práticas no Brasil. Physis Revista da Saúde Coletiva, Rio de Janeiro, v. 20, n. 3, p. 995-1.015, 2010.

SANTOS, V. E.; MATTOS, R. B.; FREI, A. Redução de danos em Caps AD: para além do pragmatismo e da estratégia de intervenção - experiências do Capad Santana. In: GODOY et al. Fórum Estadual de Redução de Danos de São Paulo. São Paulo: Córrego, 2014. p. 39-53.

SILVEIRA, R. W. M da; D’TÔLIS, P. O. A.O. Impactos da ação de agentes redutores de danos segundo profissionais da rede SUS. Revista da Abordagem Gestáltica, Goiânia, v. 22, n. 1, p. 79-88, 2016.

SIMMEL, G. The Sociology of Georg Simmel. Lllinos: Free Pass, [1908], 1950.

SOUZA, K. M. de; MONTEIRO, S. A abordagem de redução de danos em espaços educativos não formais: um estudo qualitativo no estado do Rio de Janeiro, Brasil. Interface, Comunicação Saúde Educação, São Paulo, v. 15, n. 38, p. 833844, 2011.

VALIM, D.; ZALUAR, A.; SAMPAIO, C. Uma etnografia das cenas de uso de crack no Rio de Janeiro e seus efeitos nos usuários. In: TEIXEIRA, M.; FONSECA, Z. Saberes e práticas na atenção primária à saúde: cuidado à população em situação de rua e usuários de álcool, crack e outras drogas. São Paulo: Hucitec, 2015. p. 201-2016.

VAZ, R. O. F. Redução de danos, política do comum, invenção de um cuidado de si: uma cartografia do Centro de Convivência É de Lei. 2015. 145 f. Dissertação (Mestrado em Psicologia Social) - Pontíficia Universidade Católica de São Paulo, São Paulo, 2015.

VERNAGLIA, T. V. C.; VIEIRA, R. A. M. S.; CRUZ, M. S. Usuários de crack em situação de rua - características de gênero. Ciência \& Saúde Coletiva, Rio de Janeiro, v. 20, n. 6, p. 1.851-1.859, 2015.

VÍCTORA, C. G.; KNAUTH, D.; HASSEN, M. N. Pesquisa qualitativa em saúde. Porto Alegre: Tomo Editorial, 2001.

VIEIRA, J. K. S. et al. Concepções sobre drogas: relatos dos usuários do Caps-AD, de Campina Grande, PB. Revista Eletrônica de Saúde Mental (Smad), São Paulo, v. 6, n. 2, p. 274-295, 2010. 